\title{
ApPlication of RaPid Prototyping Technologies to Wind TunNel Testing of High-Performance Vehicles
}

\author{
Bruno R. M. Padilha ${ }^{1}$, César A. D. Rodrigues ${ }^{2}$, Guilherme N. Barufaldi ${ }^{3}$, e Roberto G. A. da \\ Silva $^{4}$ \\ ${ }^{1}$ IAE- Instituto de Aeronáutica e Espaço \\ 2,3,4 ITA- Instituto Tecnológico de Aeronáutica \\ E-mails: bruno.massucatto@ gmail.com, cduarte2003@hotmail.com, \\ guilherme.barufaldi@protonmail.com, rgannes1@gmail.com.
}

Aerodynamics is a crucial area in high-performance vehicle design. Downforce determines turn performance and drag limits maximum speed in straight lines. To obtain the best aerodynamic design, engineers resort to many tools such as computational fluid dynamics (CFD) and multidisciplinary design optimization (MDO), in order to test designs, predict characteristics and optimize shape. However, every design that will be produced has to be validated in wind tunnels, which are employed to evaluate numerical predictions, and to correct aerodynamic elements shape, position, and incidence. Automotive wind tunnel test models are usually manufactured with machined aluminum, through a slow and expensive machining process. In this paper, we present a method developed at the Aeronautics Institute of Technology (ITA) to reduce test model manufacturing costs. We applied the fused filament fabrication (FFF) technology to build wind tunnel models, with polylactic acid (PLA) as raw material, obtaining a cheaper and faster process. A prototype was tested in the subsonic wind tunnel TA-2, located at the Institute of Aeronautics and Space (IAE), in São José dos Campos, Brazil. The results suggest that this method could become a powerful tool for productivity in automotive research and development.

\section{INTRODUCTION}

The aerodynamic design is a crucial factor for the success - or failure - of a modern competition vehicle. With the advancements of computers and softwares, tools such as computational fluid dynamics (CFD) have become increasingly popular, and are now an integral part of aerodynamic design and optimization. However, despite the importance of numerical tools, traditional experimental procedures such as wind tunnel testing are still extremely important.

By concept, [1] defines that the basic idea behind wind tunnel testing is the possibility of recreating the air flow around an object - in scale or actual size - in a static or dynamic fashion. From an engineering standpoint, this allows the observation of aerodynamic phenomena and its consequences without the risk of an actual flight.

However, the construction and operation of a large wind tunnel can be very costly. Depending on size and complexity, the test models can cost a few million dollars. Due to these conditions, research wind tunnels are usually built with smaller test chambers, in such a way that the test 
models are made in scale, which helps to reduce costs, but introduce experimental limitations and scale factors.

In academia, where wind tunnels are not usually operated for commercial purposes, the test model manufacturing costs can be even more restrictive. Historically, test models were handcrafted using wooden structures and special clays. The evolution of machining tools and processes allowed test models to be manufactured with steel and aluminum alloys, with higher mechanical resistance and level of detail. This evolution can be clearly observed in Fig. 01, where an older wooden model manufactured at ITA (Fig. $01 \mathrm{~A}$ ) is compared to a new model of an Embraer E-170 (Fig. $01 \mathrm{~B}$ ), manufactured in aluminum alloy using modern machining techniques - the greater complexity and level of detail can be observed in the high-lift devices on the wing.

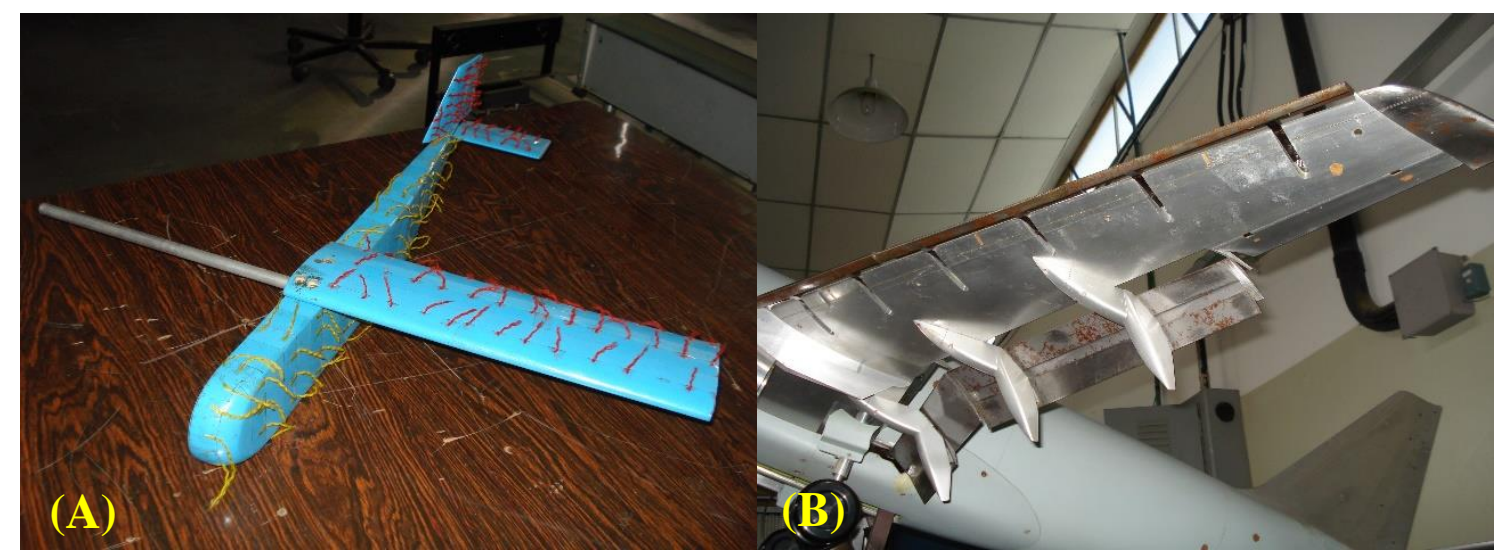

Figure 01 - Examples of wind tunnel test models: in (A), handcrafted in wood; in (B), a model of an Embraer E170 manufactured in aluminum alloy using modern techniques. Source: authors' personal collections.

As can be observed in Fig. 01 (B), the test models manufactured with modern machining processes present a greater level of detail and complexity. However, these processes are expensive and the manufacturing costs can become prohibitive, especially for universities or small companies. With this fact in mind, a team from the Aeronautics Institute of Technology (Instituto Tecnológico de Aeronáutica - ITA), in São José dos Campos, Brazil, started to experiment with new additive manufacturing technologies, with the goals of reducing test model manufacturing costs and increasing the level of detail achieved, especially for complex geometries - such as multi-element airfoils, high-lift devices and diffusers - while still maintaining acceptable mechanical resistance and surface finishing. Some interesting results have been achieved and can be found in [2] and [3].

An example of innovation and pioneering in the development of a competition vehicle, the Project 424 was conceived to be designed in an open platform environment, i.e., people from around the world can volunteer to cooperate in the development, working in many engineering areas, in order to integrate information through an online platform. Led by Nicolas Perrin, a renowned engineer that has worked in the main categories of motorsport, Project 424 main objective is to develop a hybrid-electric vehicle according to the FIA-WEC (World Endurance Championship) P1 Class rules. Recently, the project had its objectives redirected, focusing on the development of an all-electric vehicle, with fully autonomous control. The collaboration with Project 424 became an ideal opportunity for the team at ITA to further develop and test the new model manufacturing methodology, and also to acquire new knowledge in experiments with high performance vehicle aerodynamics. 


\section{OBJECTIVES}

The main objective of the present work was to build a wind tunnel test model in 1:5 scale (20\% the size of the actual vehicle) and subject it to wind tunnel experiments. Analyses of the results were made through drag and downforce versus airspeed charts, and flow visualization with tufts.

A secondary objective of the experiment was to analyze the structural behavior of the test model, when subjected to aerodynamic loads. This qualitative analysis was important to observe deformation, displacements, excessive flexibility and if any cracks or failure points could appear.

Another secondary objective of the experiment was to control budget and costs, and also to analyze cost growth due to unforeseen problems - due to the pioneering character of the proposition, there were no previous references and cost estimation methodologies were considered unreliable.

\section{MATERIALS AND METHODS}

\subsection{Fused filament fabrication}

FFF is one of the most widespread 3D printing technologies, due to its low cost, and ease of raw material storage and handling. Its operation principle is quite simple: a filament of raw material is unwound from a coil and supplied to a heated printer extruder head; inside the head, the material is softened by heating, and deposited on the part being manufactured, layer by layer. As the piece grows, it is moved away from the head, in order to keep a constant distance between the head nozzle and the surface receiving material. Because of this form of operation, the surface of the prototype is usually rough.

Two different raw materials were tested: acrylonitrile butadiene styrene (ABS), and polylatic acid (PLA). ABS is a copolimer thermoplastic, very popular for use in 3D printing. It has good impact absorption capacity and limited elastic characteristics. However, this material has poor thermal dissipation properties, which can result in contractions and cracks. The first airfoil prototype was manufactured in ABS but, due to the aforementioned issues, showed cracks caused by material contraction, as can be observed in Fig. 02. This problem was not encountered in prototypes manufactured with PLA, which proved to be a better material and, therefore, was selected. 


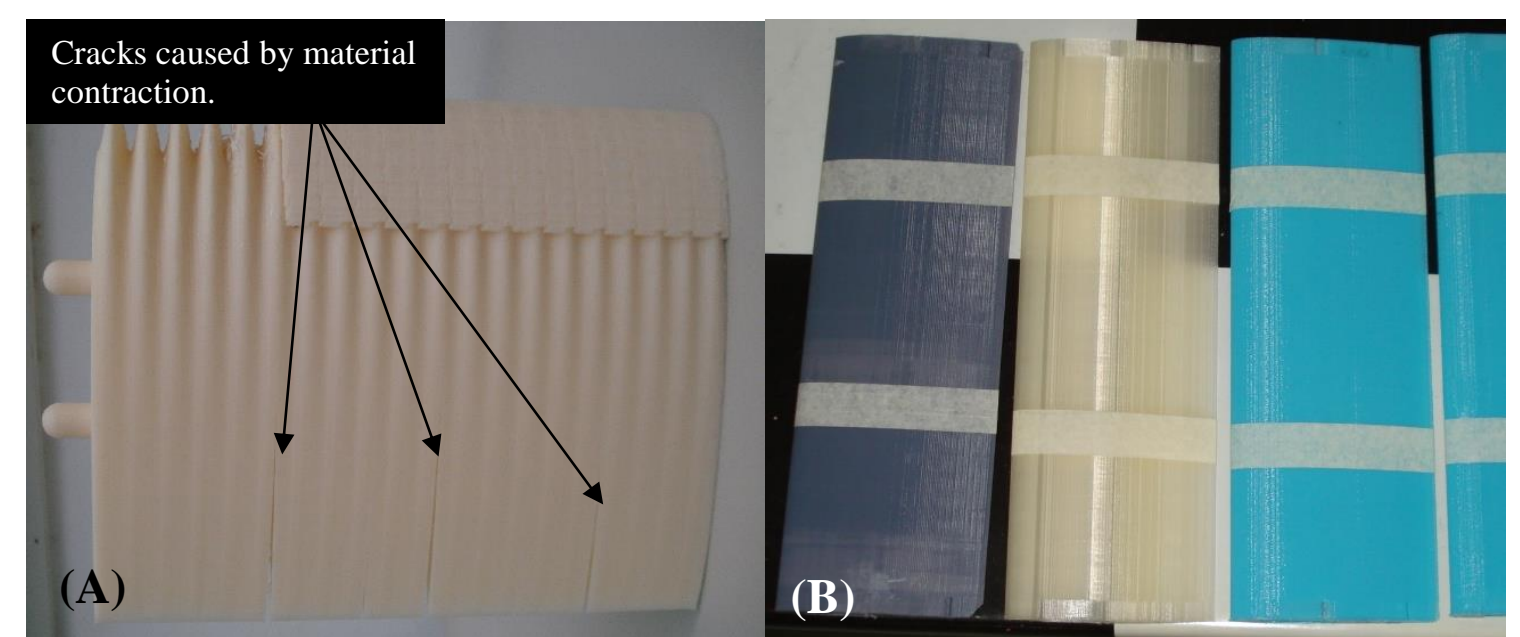

Figure 02 - Comparison between airfoil prototypes manufactured with ABS (A) and PLA (B). Note the cracks caused by material contraction on the ABS prototype.

\subsection{Test model design}

In order to be used in a wide range of dynamic pressure values, the vehicle test models must be able to withstand the loads in all aerodynamic range. Since the plastic material has a limited mechanical resistance, internal structures were conceived in order to reinforce the prototype. Consisting of spars and rods made of SAE 1020 steel, these structures substantially increased overall stiffness, so that the bending and twisting deformations were negligible on the chassis. These structures can be used to hold joints and sockets, since they are significantly stiffer and more resistant, and also act as support for the fixation rod. One of the designed airfoils is shown in Fig. 03, illustrating the internal structure [3].

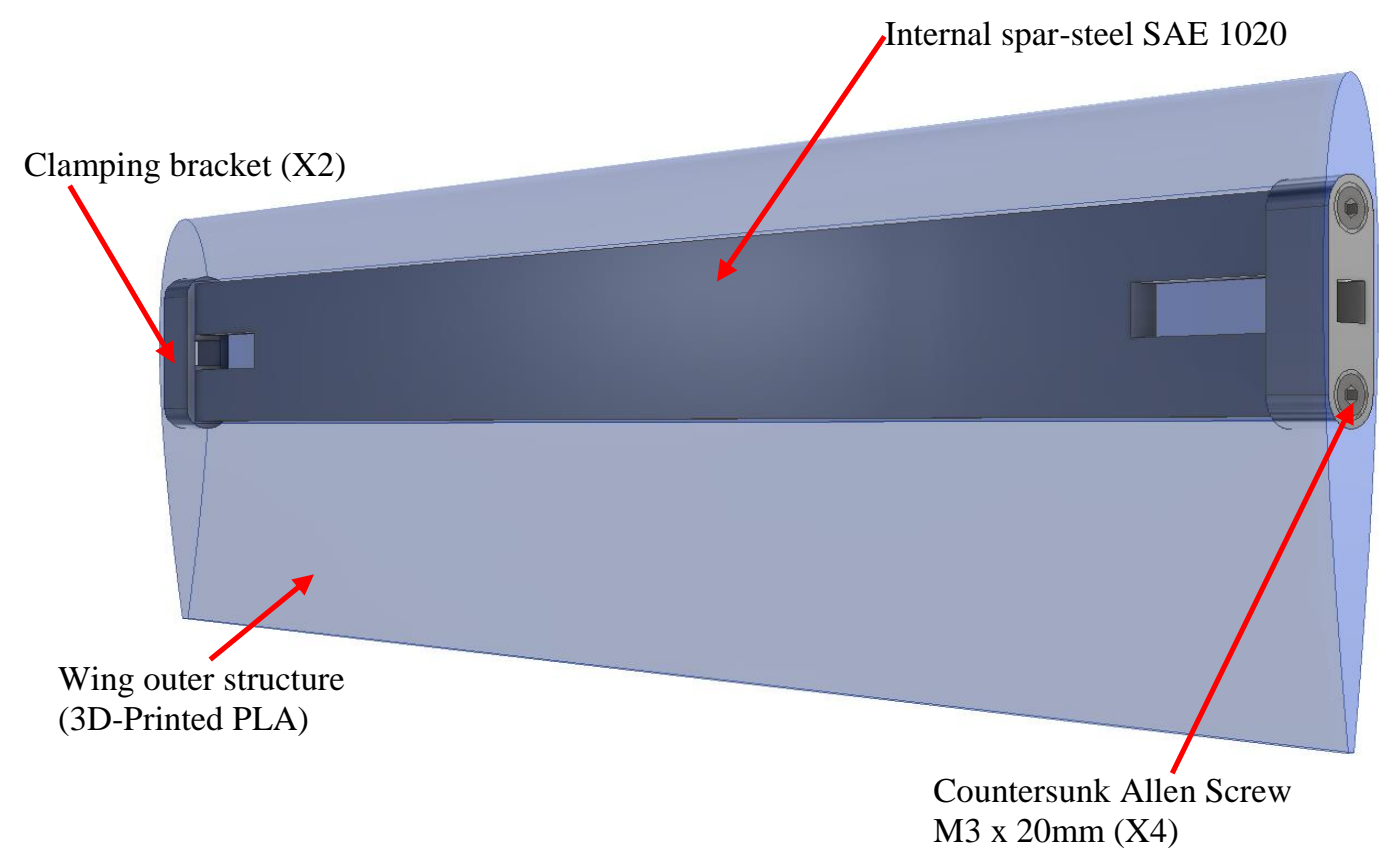

Figure 03 - Final design of the wing and its complementary elements.

The methodology was initially developed as a Master's degree research [3] for manufacturing wing and airfoil test models for the transonic wind tunnel at IAE, and also to support the experimental works in [2], which involved the creation of complex wavy wing leading edge 
geometries, that could hardly be built with traditional metal machining methods. Due to the pioneering character of the proposition and the newness of the technology, there were very few reliable bibliographical references at the time of development, between 2016 and 2017 [3].

\subsection{Test model construction}

A 3DCloner DH 3-D printer was employed for manufacturing the chassis. This printer allows a printing volume of $320 \times 210 \mathrm{~mm}$ basis, with a maximum height of $400 \mathrm{~mm}$ [6]. These dimensions constitute a limiting factor for the size of the model, which made it necessary to divide the chassis into smaller pieces. Another important point was to observe qualitatively the overall shape, in order to identify edges that were more favorable to joining the parts together. Figure 04 shows the parts before the assembly process.

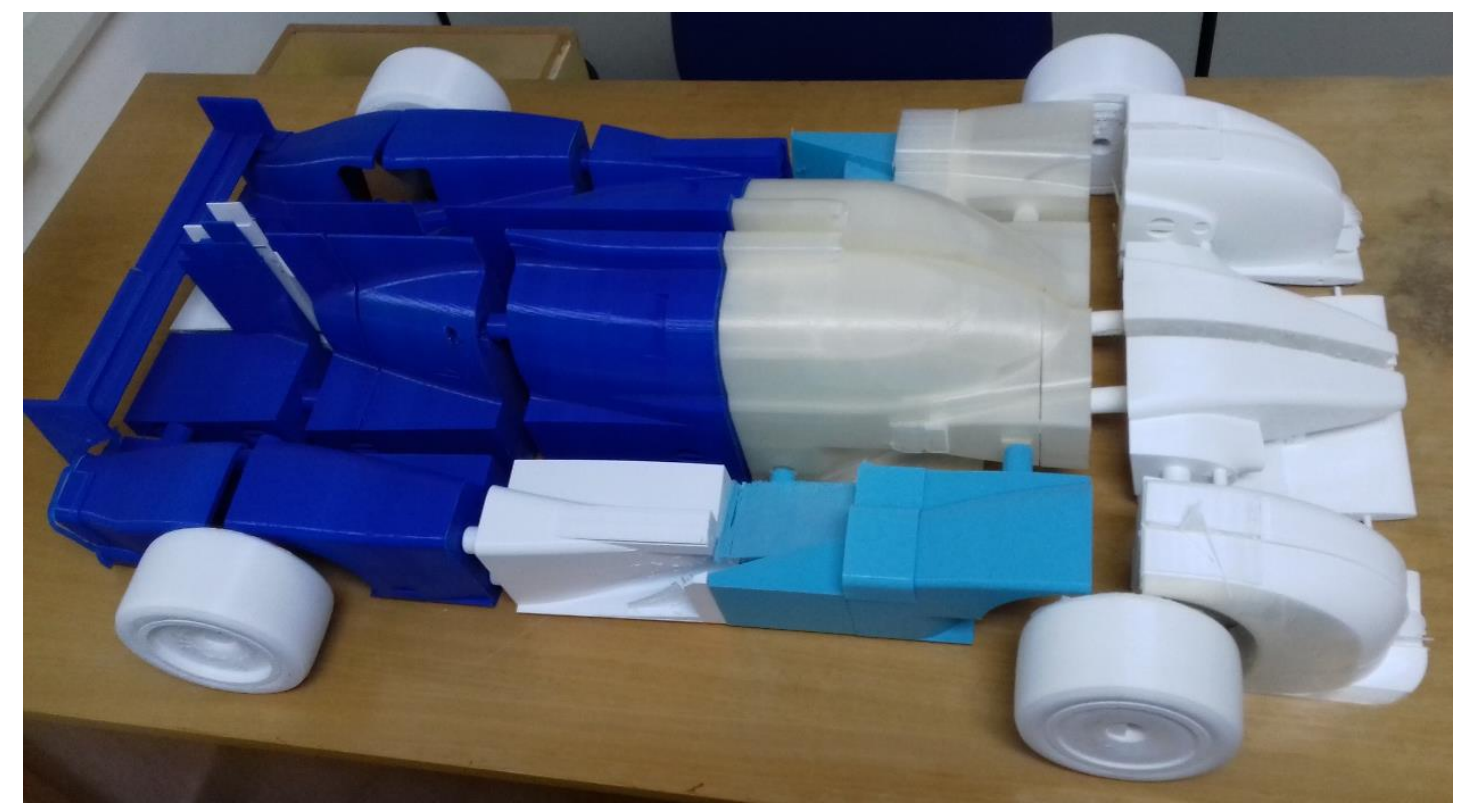

Figure 04 - Printed parts before the assembly process.

The 3D-printed parts required hand finishing before assembly, in order to remove burrs and minor imperfections. The parts were assembled and glued, and a template was used to ensure proper alignment. After the assembly process, layers of self-leveling epoxy resin were applied to correct surface roughness, as suggested in [3]. Both the assembly process and the application of resin require a considerable level of manual skill, in order to avoid misalignment, warping, and resin accumulations. One has to apply constant brush movements until resin curing point, when brush marks become more defined - at this point, brushing is stopped. Figure 05 shows the resin application process, as well as the glassy finishing on the model surface. 


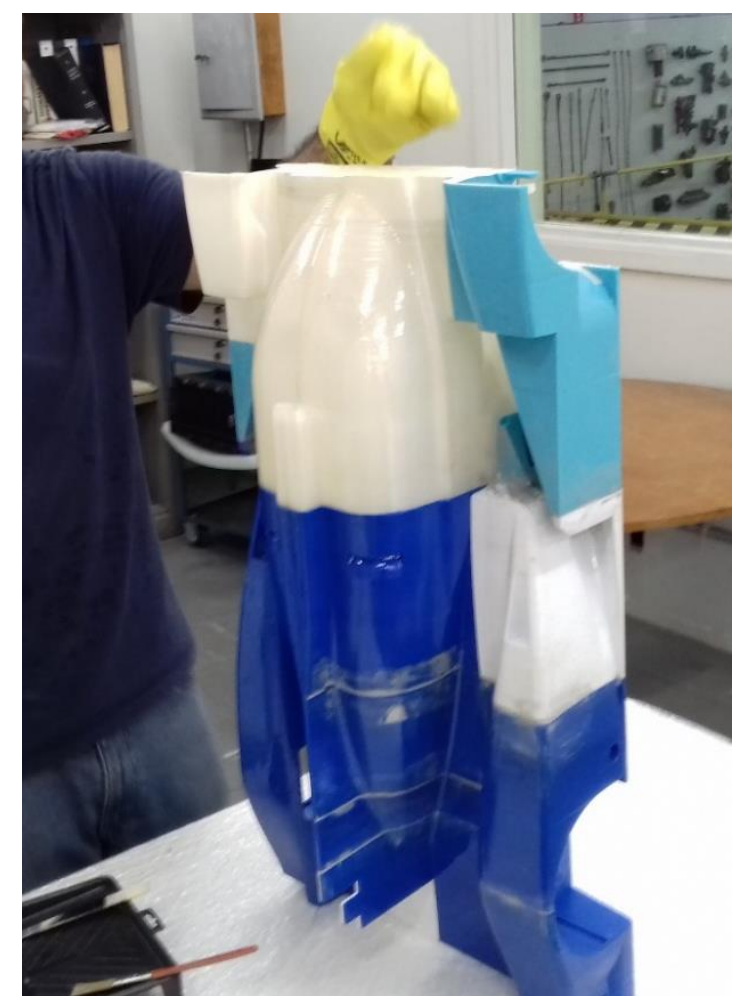

Figure 05 - Epoxy resin application for surface roughness correction.

After the resin is cured, the surface must be sanded for leveling and removal of bubbles and imperfections. After sanding, a polyurethane-based paint is applied. Since the model will be used for other flow visualization methods, such as colored oil, a matte black color was chosen for the paint. The final result is shown in Fig. 06.

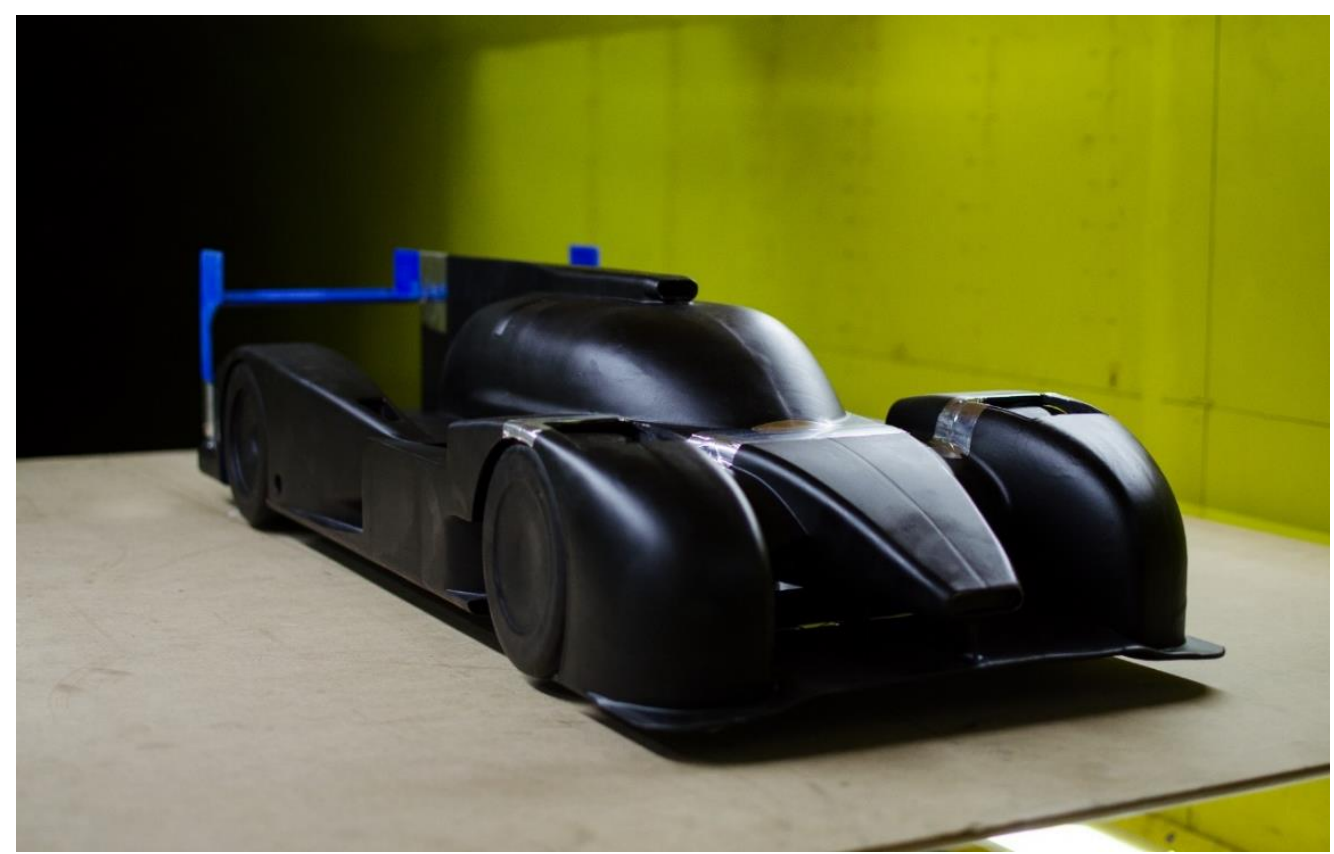

Figure 06 - Finished test model inside a wind tunnel, after the manufacturing process developed in [3]. 


\subsection{The TA-2 wind tunnel}

The experiments were conducted at the TA-2 subsonic wind tunnel, at the Institute of Aeronautics and Space (IAE), which belongs to the Department of Aerospace Science and Technology (DCTA) of the Brazilian Air Force. The TA-2 is a closed circuit wind tunnel, with a test chamber $3 \mathrm{~m}$ wide, $2 \mathrm{~m}$ high and $3 \mathrm{~m}$ long. Powered by a $1800 \mathrm{hp}$ electric motor, the tunnel can provide airspeeds up to $140 \mathrm{~m} / \mathrm{s}$ at the test chamber. The chamber also features an aerodynamic balance capable of measuring forces in three axes $(\mathrm{X}, \mathrm{Y}, \mathrm{Z})$, and the corresponding moments [4]. This wind tunnel was designed to be used in aeronautical experiments, however, its test chamber can be adapted to accommodate other types of experiments, such as vehicular tests (busses, trucks and cars), as well as experiments with buildings and constructions.

Wind tunnels specifically designed for vehicular tests have some peculiarities that differentiate them from tunnels designed for aeronautical use. The main difference is a moving belt on the ground, to simulate the relative of the vehicle to the ground. The need for such a device, according to [5] is justified because a boundary layer is formed, attached to the wind tunnel walls. In aeronautical wind tunnels, the test model is usually located at the center of the test chamber, away from the walls. These differences are illustrated in Fig. 07, where both types of wind tunnels are shown.

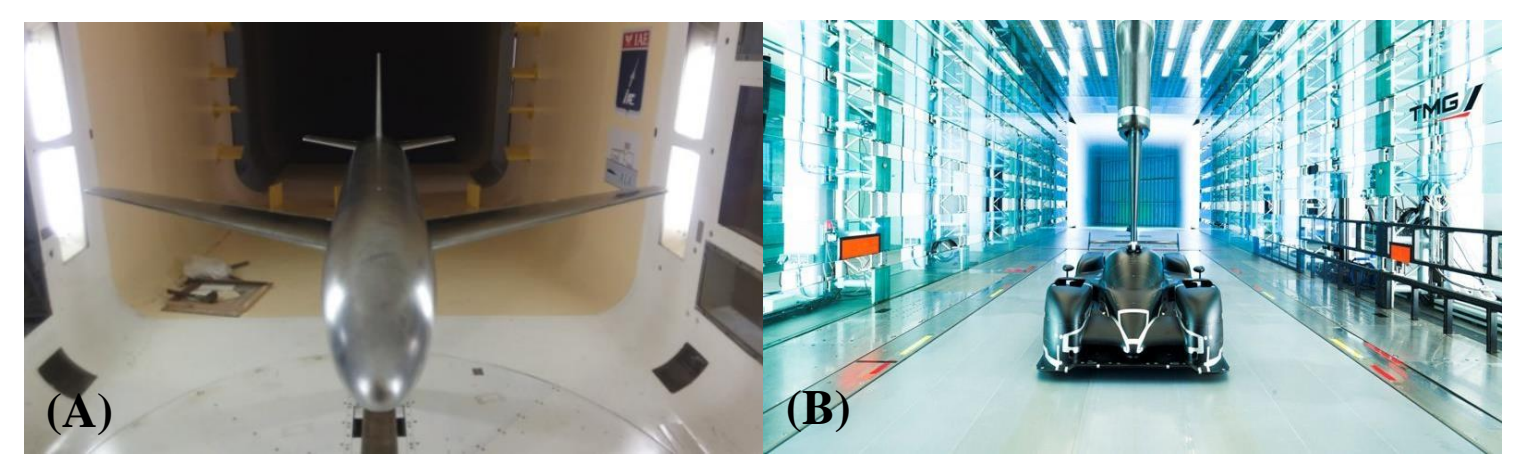

Figure 07 - (A) Test chamber of the TA-2 (aeronautical wind tunnel), with a test model at the center, and the support connected to the inferior wall; and (B), an automotive wind tunnel at Toyota GmbH, in Köln, Germany, where the moving belt can be observed underneath the test model (notice the balance arm above).

As presented in [1], it is possible to conduct vehicular experiments in aeronautical wind tunnels with good results, provided some minor adaptations are made. Historically, during the 1970 and 1980 decades, many automotive experiments were conducted at TA-2, the most famous being the aerodynamic tests during the development of the racing car prototype for the Brazilian Formula 1 team Fittipaldi-Coopersucar (the test model is shown in Fig. 08). In these occasions, the main adaptation made was the elevation of the tunnel floor at the center of the test chamber, in order to reduce the boundary layer thickness - a new layer is formed over the elevated platform, but is significantly thinner. Unfortunately, the devices were lost, and a new elevation platform had to be manufactured. 


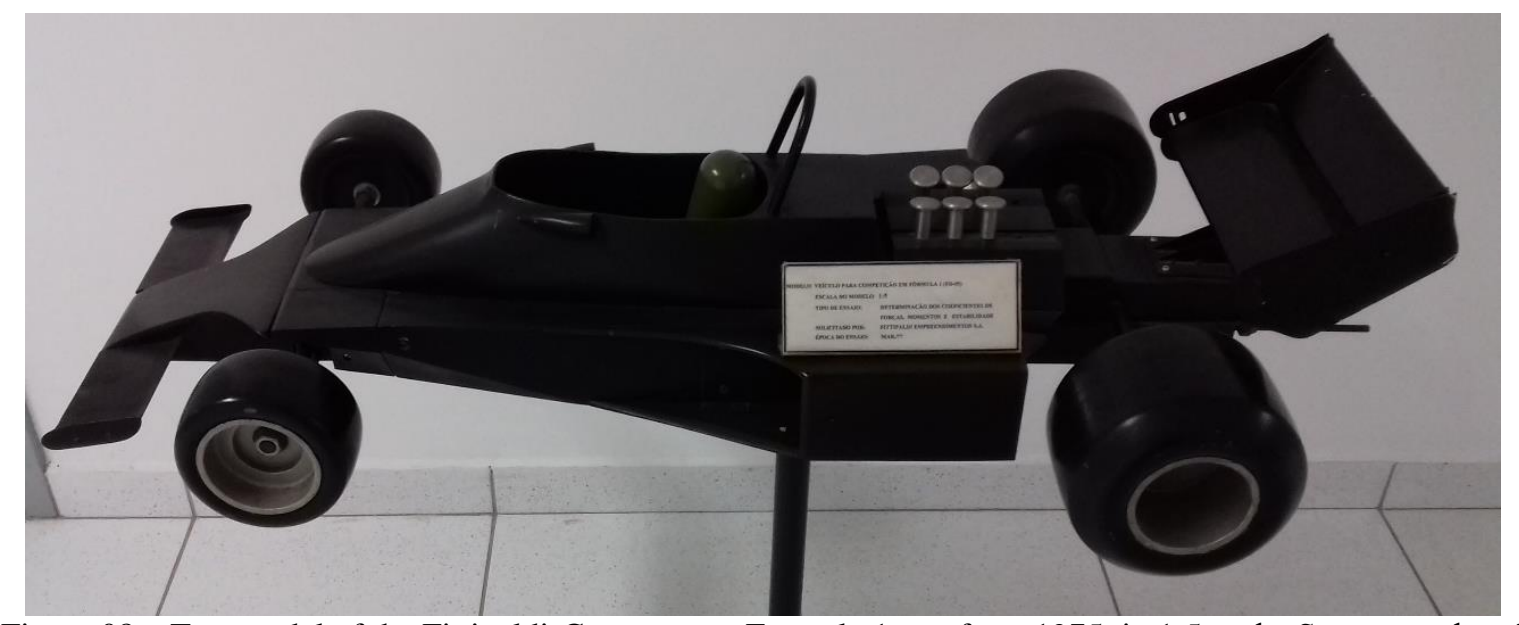

Figure 08 - Test model of the Fittipaldi-Coopersucar Formula 1 car, from 1975, in 1:5 scale. Source: authors' personal collections.

To design the new elevation platform for vehicular experiments, three requisites had to be met:

- Wind tunnel test chamber dimensions;

- Test model dimensions;

- Types and dimensions of the balance arms.

The dimensions of the elevation platform floor plate were determined according to the criteria presented in [1], which recommends that the plate width must be at least three times that of the test model, and that the plate leading edge must be placed ahead of the test model leading edge, but with an advancement ratio not exceeding $20 \%$ of the test model length. The balance arm top is located at approximately $250 \mathrm{~mm}$ above the wind tunnel floor, far above the tunnel floor boundary layer. The final dimensions of the elevation platform - plate and elevation structure - are shown in Fig. 09. The supporting structure was manufactured in SAE 1020 steel. The platform is fixed to a rotating platform on the wind tunnel floor by nuts and bolts. This rotating platform is part of the wind tunnel and allows adjustments to ensure perfect alignment to the air flow.
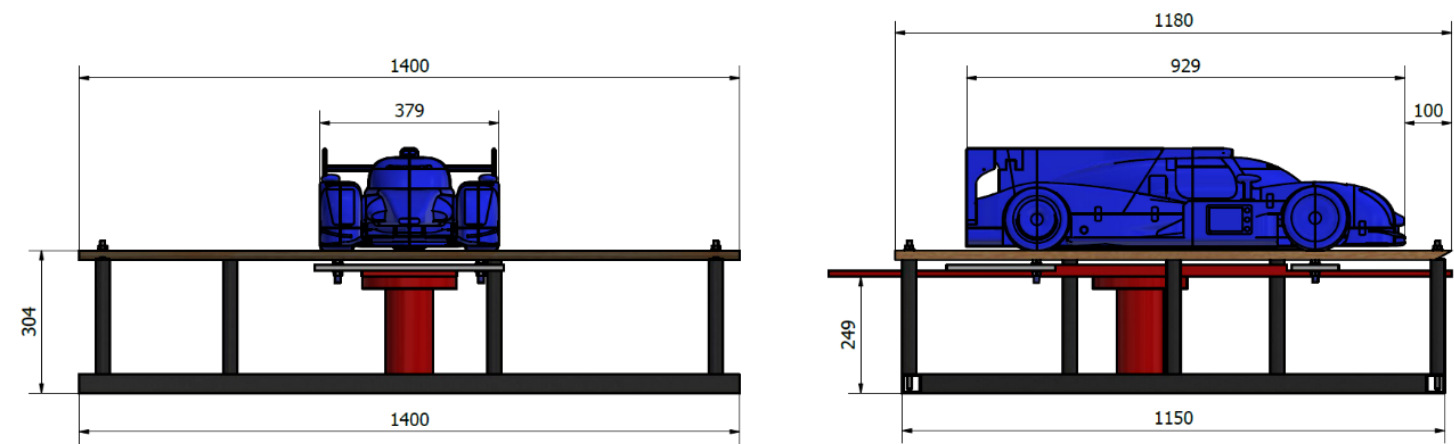

Figure 09 - Layout and dimensions of the elevation platform designed for vehicular experiments at the TA-2 wind tunnel.

The final assembly of the model and elevation platform inside the wind tunnel test chamber is shown in Fig. 10. Notice that both the test model and the balance arm are not fixed to the elevation platform, so that the aerodynamic forces are due to the model and the arm alone - the balance arm drag must be subtracted from the final results, and is measured before the test model is attached. 


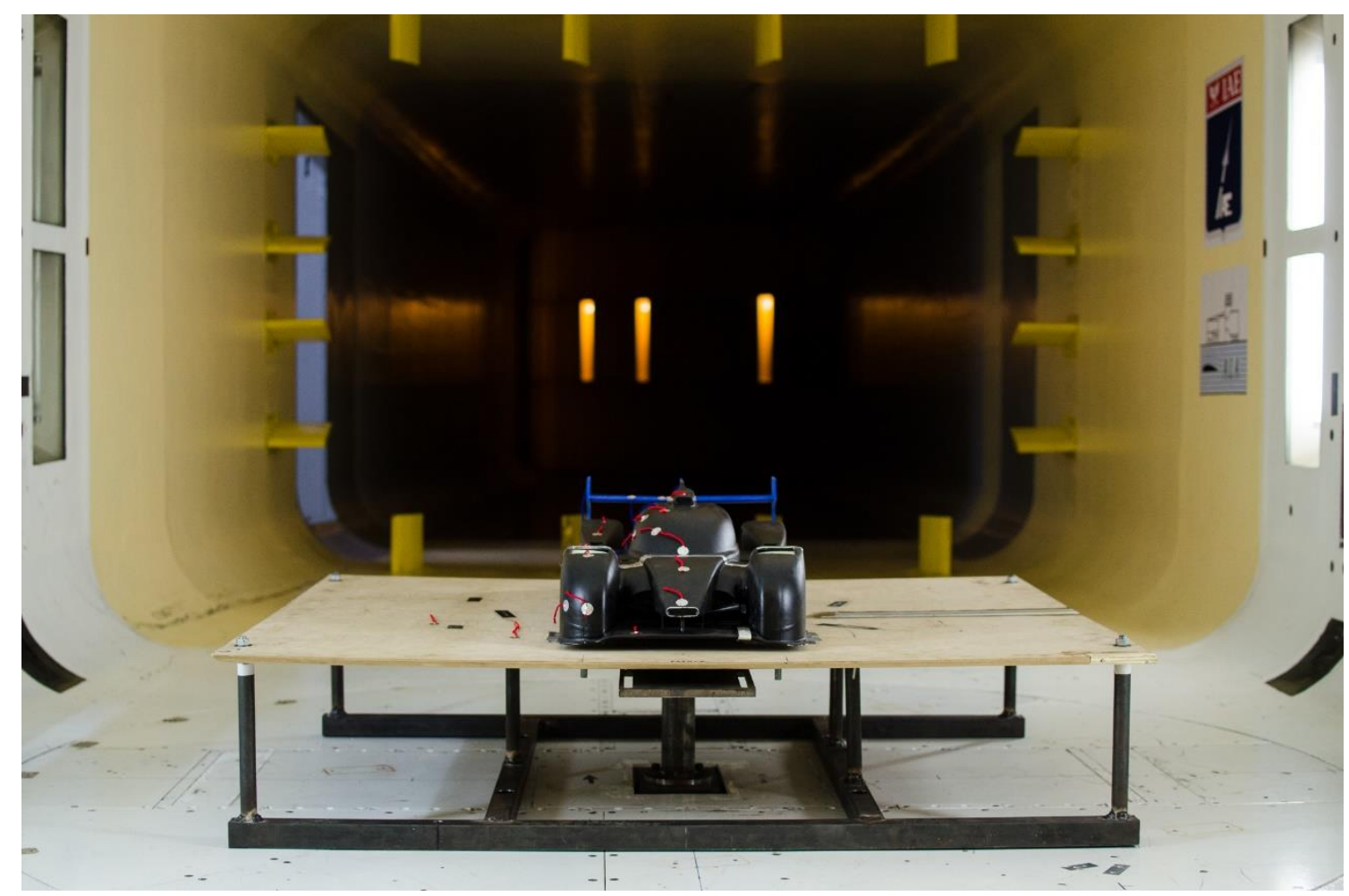

Figure 10 - Final assembly of the test model and elevation platform on the TA-2 test chamber.

\section{RESULTS AND DISCUSSION}

\subsection{Experiment matrix}

The experiment matrix is built with the goal of organizing the wind tunnel runs, such as to divided and establish airspeed values and other conditions. The planned airspeed sweep started at $20 \mathrm{~m} / \mathrm{s}$ and was carried up to $70 \mathrm{~m} / \mathrm{s}$. Table 01 shows the planned and actual (obtained) airspeed values, plus measurement uncertainties - in each test run, the percentual uncertainty is $\pm 0.2 \%$, according to [4].

Table 01 - Experiment matrix with planned and actual airspeeds obtained in each test run, and associated

\begin{tabular}{|c|c|}
\hline \multicolumn{2}{|c|}{ uncertainties. } \\
\hline Planned airspeed $(\mathbf{m} / \mathbf{s})$ & Actual airspeed $\mathbf{0 . 2 \%}(\mathbf{m} / \mathbf{s})$ \\
\hline 20 & $20.43 \pm 0.04$ \\
\hline 30 & $30.65 \pm 0.06$ \\
\hline 40 & $40.70 \pm 0.08$ \\
\hline 45 & $45.61 \pm 0.09$ \\
\hline 50 & $51.15 \pm 0.10$ \\
\hline 55 & $56.26 \pm 0.11$ \\
\hline 60 & $61.39 \pm 0.12$ \\
\hline 65 & $66.51 \pm 0.13$ \\
\hline 70 & $71.37 \pm 0.14$ \\
\hline
\end{tabular}

According to Table 01, the airspeed progression changes from $40 \mathrm{~m} / \mathrm{s}$, and the airspeed increment is $5 \mathrm{~m} / \mathrm{s}$. This procedure was adopted for two reasons: to better observe changes in the airflow behavior, and to identify any unusual structural displacement or deformation due to the increasing aerodynamic loads. 


\subsection{Aerodynamic loads measurement}

The elevation platform, the balance arm and the fastening device remain exposed to the airflow, i.e., there no fairings covering these objects. This issue is caused by the necessary adaptations made to adapt the tunnel to a vehicular test, such as explained in Sec. 3. Therefore, the whole assembly, without the car model, is subjected to all of the airspeeds in the experiment matrix, in order to measure the drag force caused by the ensemble - the result must be subtracted from the measurements with the car model, a posteriori.

The balance is featured with a data acquisition system which produces electric pulses that allow the aerodynamic loads to be quantified. The conversion of these pulses with a calibration curve yields the aerodynamic forces in newtons. The absolute values of the forces - downforce and drag - are shown in Figs. 11 and 12, respectively. The associated measurement uncertainty is $\pm 0.2 \%$, as previously mentioned [4].

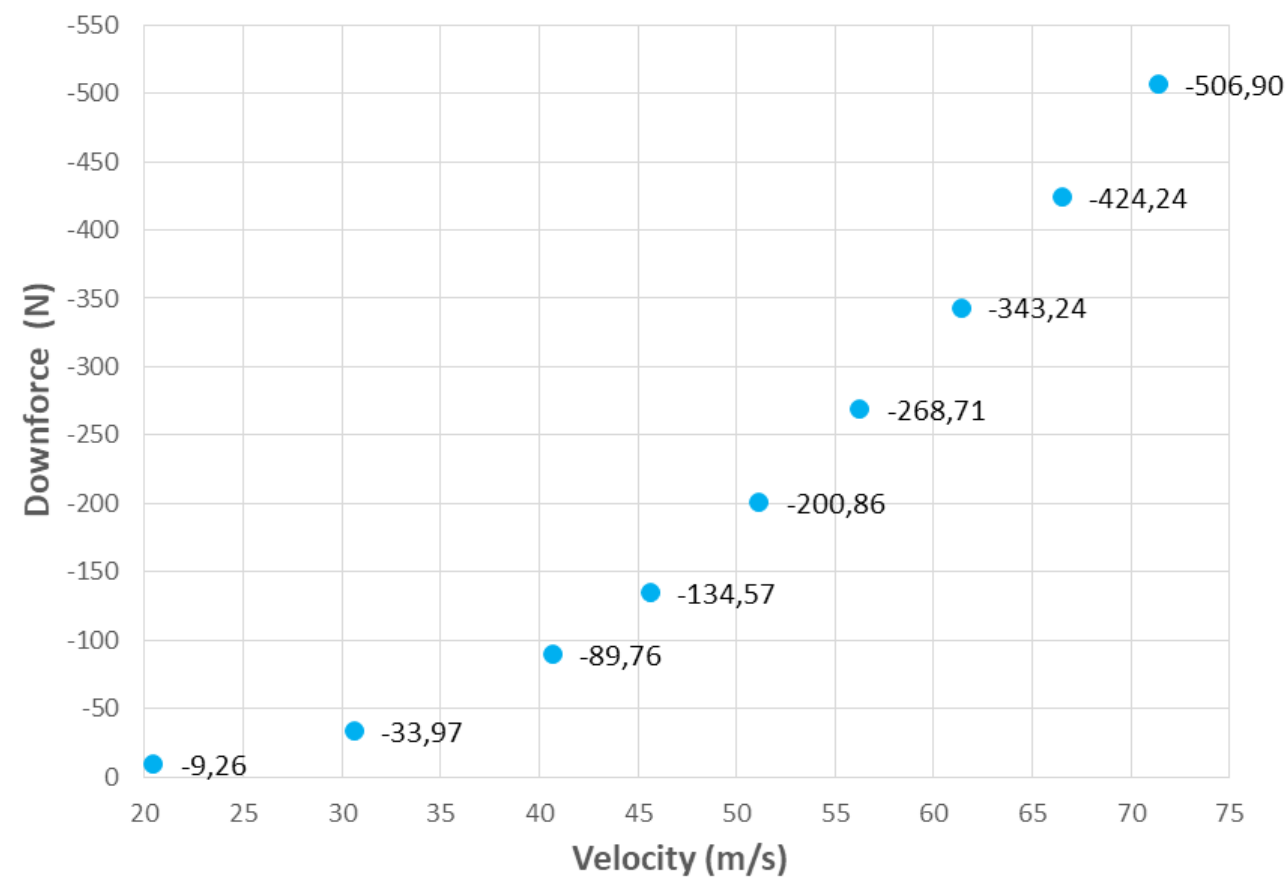

Figure 11 - Experimental results: downforce values $[\mathrm{N}]$ versus airspeed $[\mathrm{m} / \mathrm{s}]$. 


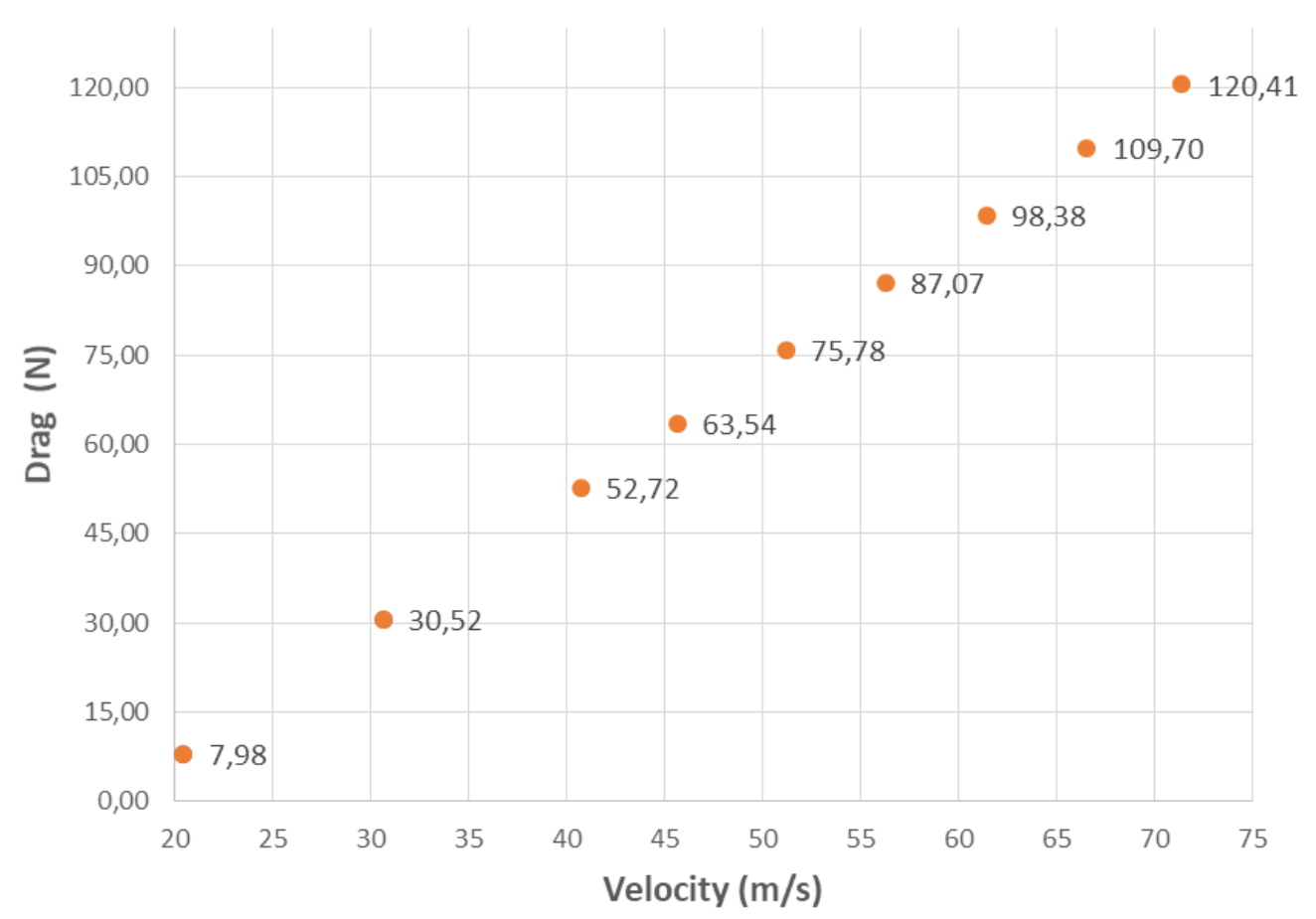

Figure 12 - Experimental results: drag values [N] versus airspeed [m/s].

\subsection{Aerodynamic coefficients calculation}

The aerodynamic data presented in Sec. 4.2 was used to obtain the aerodynamic coefficients. The data reduction process employed is suggested in [1]. Equation 01 us used for calculating the drag coefficient, and Eq. 02 for the lift (downforce) coefficient. A CAD tool was used to obtain the test model frontal projection area. In this work, we employed the Autodesk Inventor®. Figure 13 shows the frontal area projection.

Equation 01

Equation 02

$$
C_{D}=\frac{D}{\frac{1}{2} * \rho * V_{\infty}^{2} * A}
$$

$$
C_{L}=\frac{L}{\frac{1}{2} * \rho * V_{\infty}^{2} * A}
$$

Where:

$D=$ Drag in Newtons

$L=$ Downforce in Newtons

$\rho=$ Air density in $\mathrm{Kg} / \mathrm{m}^{3}$

$V_{\infty}=$ flow velocity

$A=$ frontal area of the model in $\mathrm{m}^{2}$ 


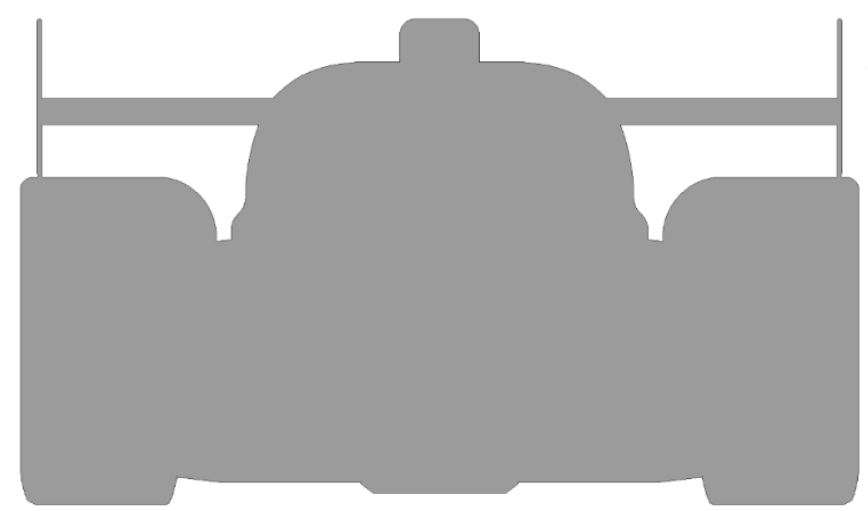

Figure 13 - Test model frontal area projection, obtained with Autodesk Inventor®.

The frontal projection area was determined for the actual size vehicle, with an estimated value of $1.6 \mathrm{~m}^{2}$. Since the scale is 1:5, the projection area of the model is $0.064 \mathrm{~m}^{2}$. Equation 01 allows the obtention of the drag coefficients, which are shown in Fig. 14.

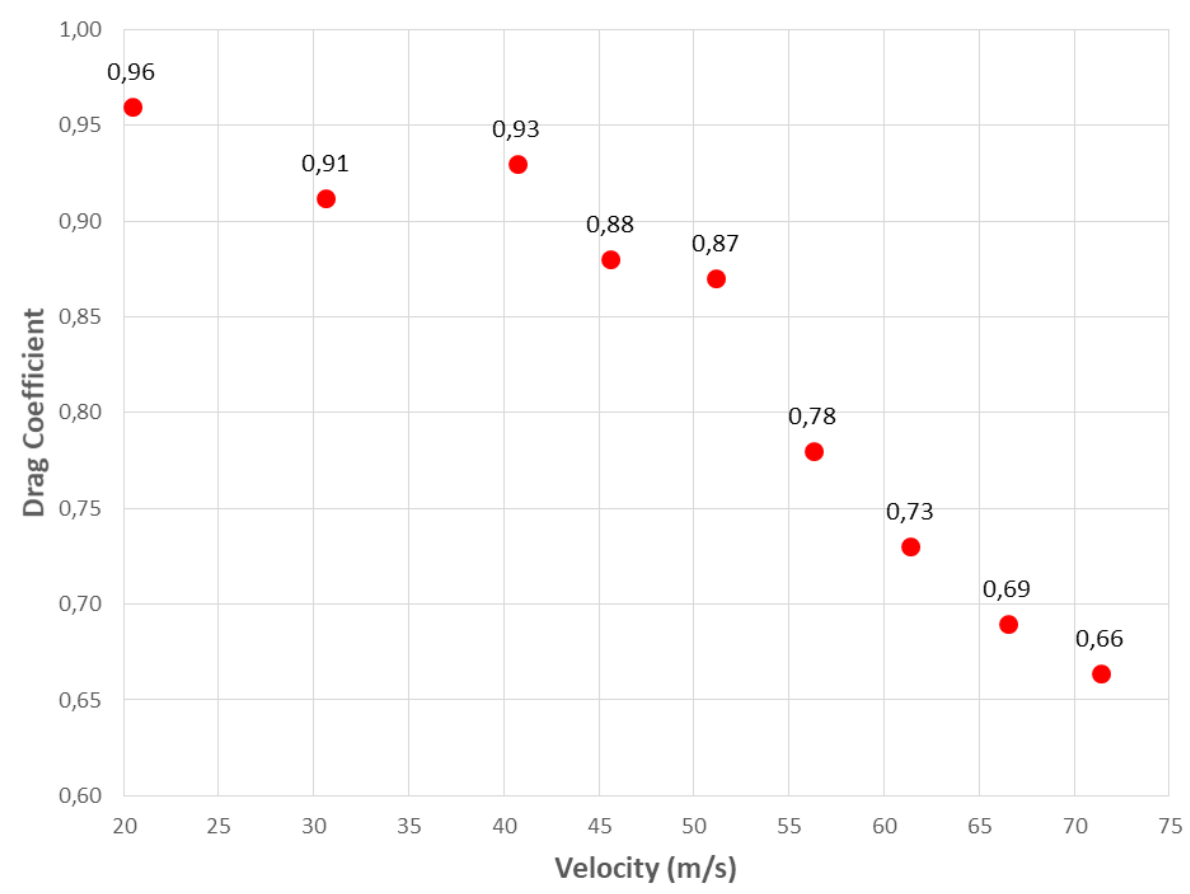

Figure 14 - Nondimensional drag coefficient values versus airspeed [m/s].

Figure 15 shows the lift (downforce) coefficient values as a function of the airspeed, as obtained with Eq. 02. 


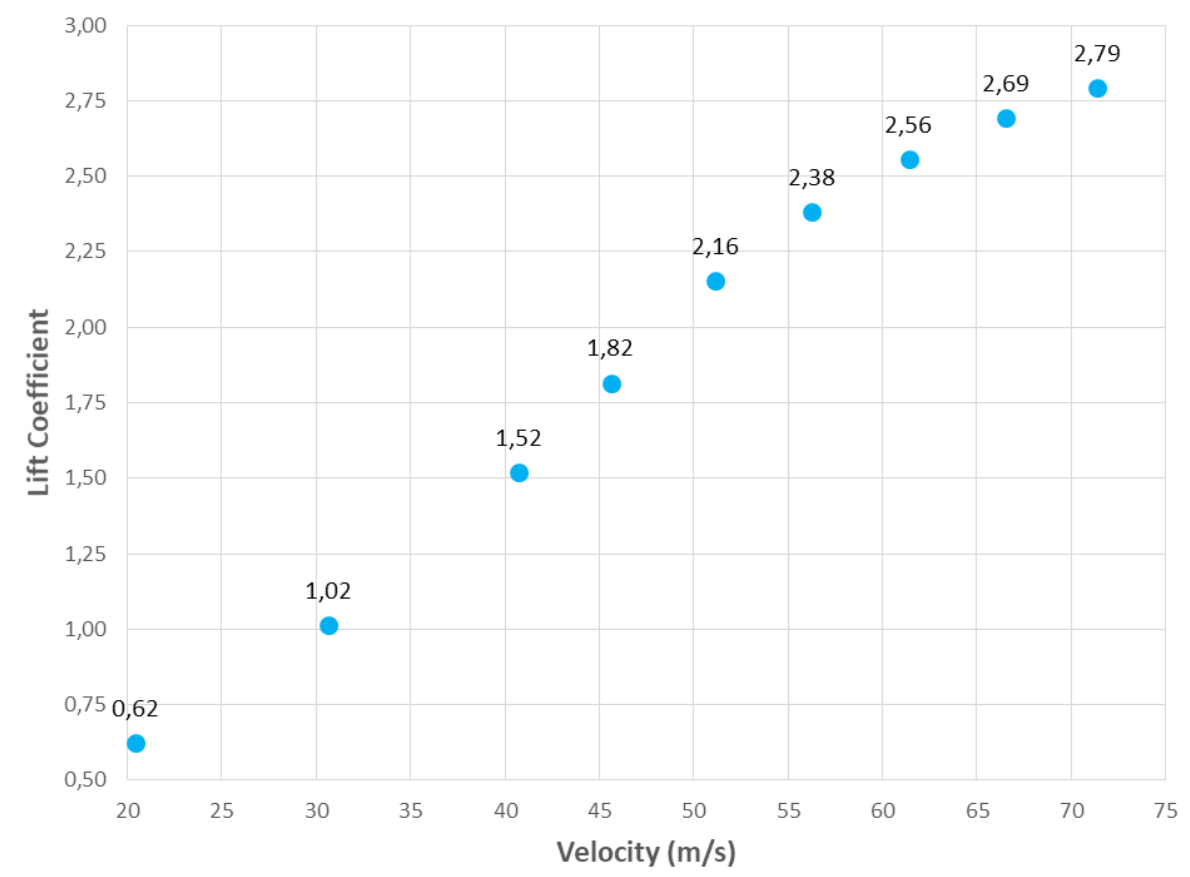

Figure 15 - Nondimensional lift (downforce) coefficient values versus airspeed [m/s].

\subsection{Comparison of coefficients with CFD results}

In order to further investigate the results and obtain a feasible standard for comparison, some airspeed values and results were compared to CFD results. Project 424 CFD analysis team provided downforce and drag data for comparison, for $50 \mathrm{~m} / \mathrm{s}$ airspeed. Table 02 shows the data comparison.

Table 02 - Comparison between coefficients: measured in the wind tunnel experiment and calculated with CFD analysis.

\begin{tabular}{|c|c|c|c|}
\hline Data source & Airspeed [m/s] & $\boldsymbol{C}_{\boldsymbol{L}}$ & $\boldsymbol{C}_{\boldsymbol{D}}$ \\
\hline CFD & 50 & 2.09 & 0.45 \\
\hline Wind Tunnel & $51.15 \pm 0.20 \%$ & 2.16 & 0.87 \\
\hline \multicolumn{2}{|r|}{ Difference (\%) } & $2.98 \%$ & $90.41 \%$ \\
\hline
\end{tabular}

\section{CONCLUSIONS}

\subsection{Analysis of results}

In Table 02, the experimental and CFD lift coefficient (downforce) values presented are very close, with a small difference of less than $3 \%$. The experimental results for downforce can be considered very satisfactory. However, the values for the drag coefficient are significantly higher, with a difference of more than $90 \%$ with respect to those predicted by CFD analysis.

These discrepancies on the drag coefficient values can be attributed to characteristics of both the tunnel and the test model, according to [1]:

- The wind tunnel is not equipped with a moving belt and the model wheels are static, which interferes with the airflow and, consequently, increases drag; 
- Scale factors that make it difficult or impossible to faithfully reproduce model details, such as floor flaps, galleries, Gurney flaps and other small parts.

In addition to the factors previously mentioned, some car details were not reproduced in the model, such as air intakes for engine and brakes cooling, and also the engine air intake - in the test model, all these intakes were blocked, completely restricting airflow and, as such, creating a "wall effect" and large drag increase, as shown in Fig. 16. The frontal areas of these intakes and inlets correspond to almost $9 \%$ of the total frontal projection area.

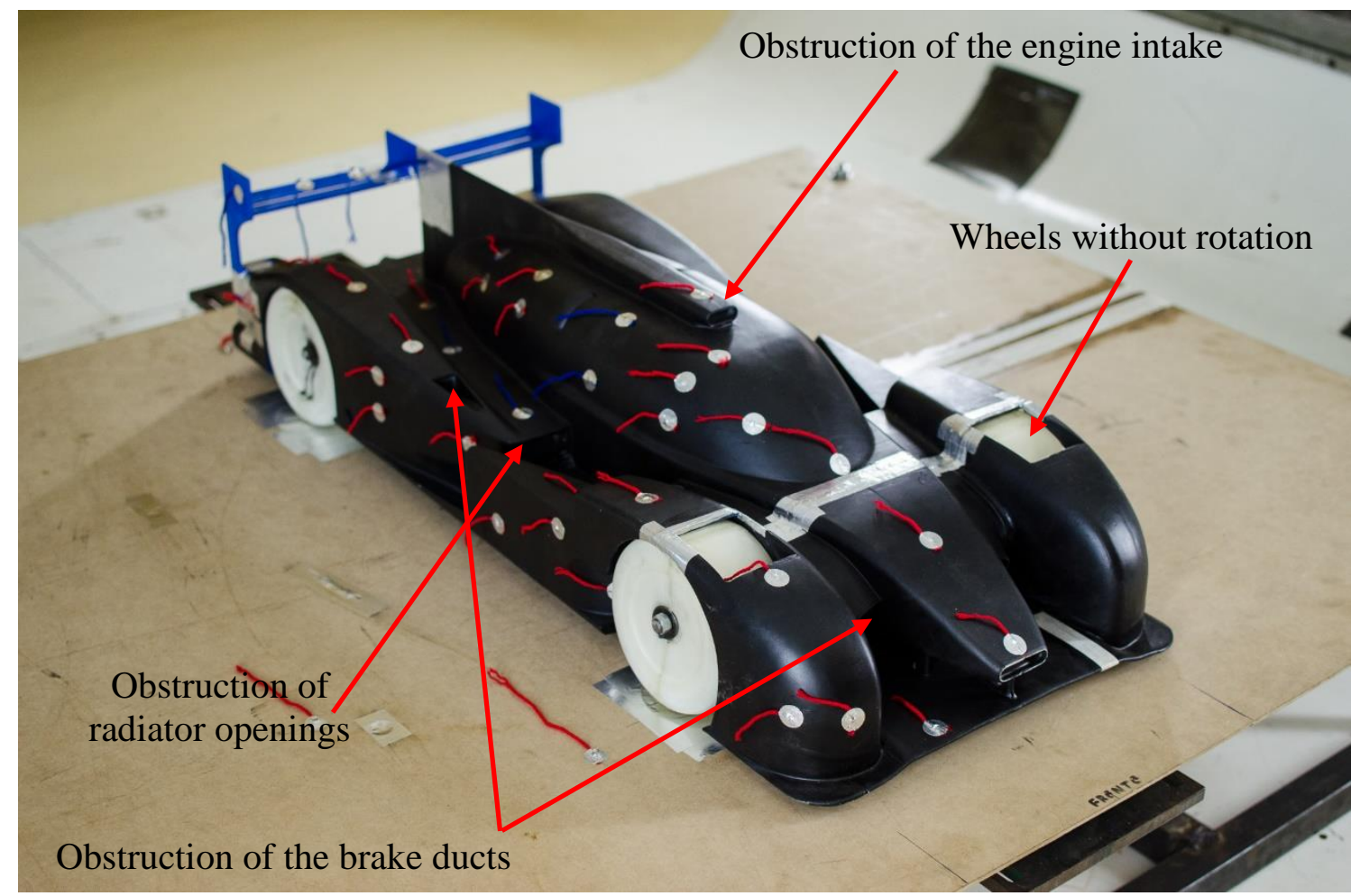

Figure 16 - Obstructions to the airflow, caused by closed air intakes, caused a large increase in drag.

\subsection{Test model analysis}

Regarding the test model performance during the wind tunnel runs, the expectations were met and, in some cases, surpassed. No occurrences of structural anomalies were identified, and the experiment could be carried without any problems. After inspection with a 3D scanner, the test model showed constructive fidelity of $95.4 \%$. Regarding costs and budgets, the results were also satisfactory. The total estimated cost, which includes more than $9 \mathrm{~kg}$ of raw material PLA, epoxy resin, paint, and production inputs - and also hardware material for joints and the elevation platform, is around US\$750.00. When compared to the estimated costs of a test model manufactured with traditional methods - machined aluminum - the cost savings are estimated to reach $95 \%$.

\subsection{Future developments}

The automotive research will be continued and the developed methods, improved. In the near future, another test model will be manufactured, and the air intakes and galleries will be designed to keep the airflow free, in order to achieve a higher degree of fidelity to the actual 
vehicle, and to minimize interferences. The new design of galleries and air intakes is shown in Fig. 17.

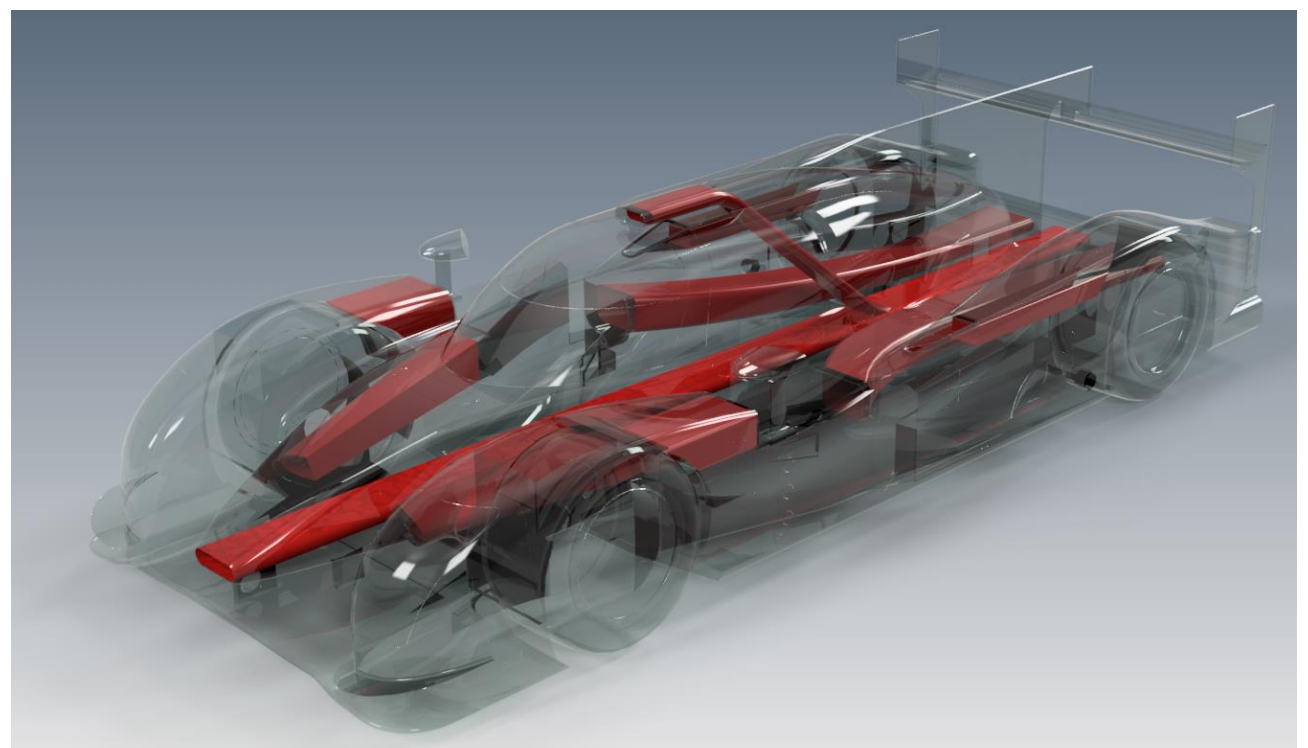

Figure 17 - Conception of the future test model, exhibiting the new fully functional air intakes and galleries.

The team also hopes that the developed methodology, and also the test model and hardware can be used for other research projects at ITA and IAE, and that the results may drive the development of the Brazilian automotive industry, especially inside the motorsport segment.

In addition to the evolution of the manufacturing processes, a future contribution could be the development of structures for simulating suspension displacements and aerodynamic interferences between the model and the ground, such as a moving belt. Another contribution could be the development of adaptations to the models in order to allow the simulation of free wheel and rotating wheel conditions. This development could be facilitated with investment contributions from research development agencies and the automotive industry, and could represent an unique and unprecedented advance for vehicular aerodynamic studies in Brazil.

\section{ACKNOWLEDGMENTS}

The authors would like to thank ITA and IAE for providing material, equipment and facilities. Special acknowledgements are due to the technicians at the Laboratório Prof. Feng at ITA, and the technicians at the TA-2 laboratory at IAE, for all the help in the manufacture, assembly and conduction of the experiment. This study was financed in part by the Coordenação de Aperfeiçoamento de Pessoal de Nível Superior - Brasil (CAPES) - Finance Code 001, under the research grant number 88882.180826/2018-01.

\section{REFERENCES}

[1] KATZ, Joseph. New Directions in Race Car Aerodynamics. Cambridge, MA: Bentley Publishers, 2006.

[2] PAULA, A. A. De. The airfoil thickness effects on wavy leading edge phenomena at low Reynolds number regime. Tese (Doutorado) - Escola Politécnica da Universidade de São Paulo. São Paulo, p. 342. 2016. 
[3] PADILHA, B. R. M. Desenvolvimento De Metodologias De Prototipagem Rápida Para O Projeto De Modelos De Ensaio Em Túnel De Vento Transônico. Dissertação de mestrado - Instituto Tecnológico de Aeronáutica, São José dos Campos, p.118. 2017.

[4] INSTITUTE OF AERONAUTICS AND SPACE. The TA-2 Subsonic Wind Tunnel. Available at: http://www.iae.cta.br/index.php/laboratorios/518-\%20laboratorios-servicossdeg-ace-tunel-aerodinamico-2

[5] BEUVAIS, F. N., TIGNOR, S. C., and TURNER, T. R., Problems of Ground Simulation in Automotive Aerodynamics. SAE Paper No. 68-0121, Detroit, 1968.

[6] 3D CLONER. Impressora 3D Cloner DH G3. Available at:

http://3dcloner.ind.br/detalhes_produto/11/impressora_3dcloner_dh_g3.html 